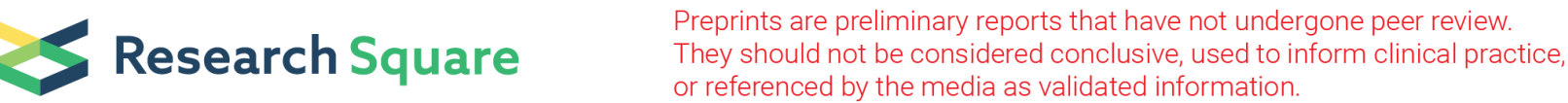

\section{Plasmon-Modulated Excitation-Dependent}

Fluorescence and Antimicrobial Activities of Silver and Gold Nanoparticles Prepared with Eugenia unifloraL. extracts

\section{Marcia Regina Franzolin}

Butantan Institute: Instituto Butantan

Daniella dos Santos Courrol

Butantan Institute: Instituto Butantan

Karina de oliveira Gonçalves

Federal University of Sao Paulo: Universidade Federal de Sao Paulo

Lilia Coronato Courrol ( $\square$ Icourrol@unifesp.br)

Universidade Federal de São Paulo https://orcid.org/0000-0002-1842-6152

\section{Research Article}

Keywords: Pitanga, silver nanoparticles, photoreduction, fluorescence

Posted Date: October 21st, 2021

DOl: https://doi.org/10.21203/rs.3.rs-924921/v1

License: (c) (1) This work is licensed under a Creative Commons Attribution 4.0 International License.

Read Full License 


\section{Abstract}

Green synthesis using plant extract is a sustainable method to obtain silver and gold nanoparticles (Ag and AuNPs) and was employed in this work. The Eugenia uniflora L. fruits and leaves extracts were used in nanoparticles synthesis. The photoreduction process with a xenon lamp and $\mathrm{pH}$ control improved optical properties and nanoparticles stability. The UV-vis, TEM, FTIR, and Zeta potential of the prepared solutions were obtained. The fluorescence spectra of Ag and AuNPs were investigated at different excitation wavelengths, which showed two kinds of fluorescence peaks. The shorter wavelength peaks red-shift with the increasing excitation wavelength, which results from the electron interband transitions, and the longer fixed wavelength peaks due to the local field enhancement. Finally, the antimicrobial tests were performed with Gram-negative and Gram-positive bacteria and Candida albicans. The best results were obtained with EuAgNPs prepared with fruits extract, photoreduction, and $\mathrm{pH} 7.0$ (with a mean of $95.12 \% \pm 10.29 \%$ of inhibition).

\section{Introduction}

Green methods to synthesize nanoparticles are inexpensive and ecofriendly[1-6]. In the green synthesis using plant extracts, phytochemicals agents can reduce silver at the same time, inhibit the ions agglomerations to produce nanoparticles[7-11]. The use of light can facilitate reduction. This process is denominated photoreduction. The formation of nanoparticles (NPs) can be triggered by photoirradiation reactions $[12,13]$. The main advantages of photochemical synthesis are the high spatial resolution, excellent versatility, and local control of reducing agents[14]. The photochemical synthesis enables NPs synthesis in various systems, for example, plants extracts[15].

Eugenia uniflora Linnaus belongs to the Myrtaceae family, with 142 genera and 5.500 species[16, 17]. Native to South America, the E. uniflora L., known as Brazilian cherry, is widely distributed in Brazil, Argentina, Uruguay, and Paraguay. The leaves and fruits of $E$. uniflora $L$. have many therapeutic properties: antimicrobial, antifungal, antiviral, antitumor, antidiarrheal, anti-helminth, insecticide, antihypertensive and anti-rheumatic effects[18-23]. The composition of E. uniflora $L$. extracts includes phenolic compounds such as flavonoids, terpenes, tannins, anthraquinones, anthocyanins, flavonoids, carotenoids, and essential oils $[16,17,23-26]$. Tannins, present in $E$. uniflora $L$. have activity against a broad spectrum of viruses: enteroviruses, caliciviruses, rotavirus, influenza virus $A$, rhabdo-virus, paramyxoviruses, human immunodeficiency virus, herpes simplex virus, adenoviruses $[27,28][29]$ and could be used hypothetically to treat the outbreak of COVID-19.

Although there are several publications reporting silver and gold nanoparticles prepared with plants extracts, little attention has been done to the fluorescence properties of these systems[30]. The interaction of light with metal nanoparticles in diameters much smaller than the light wavelength leads to the localized surface plasmon resonance (LSPR)[31]. LSPR produces the local fields greatly enhanced around the nanoparticles. Metal-enhanced fluorescence (MEF) can occur by two mechanisms: local electric field effect and intrinsic radiative decay rate effect[32]. In the first mechanism, the metal surface 
or particles produce an LSPR effect which can strengthen the local electric field. The other mechanism is that the nanoparticles can strengthen the intrinsic radiative decay rate of the fluorophore. MEF signal has been used for DNA and protein sensing[33]. Another intriguing effect is plasmon-modulated excitationdependent fluorescence (EDF). The emission peak of EDFs red-shifts as the excitation wavelength increases, which is usually explained as the red-edge effect in the multilevels[34] .

In this paper, we have employed a photoreduction method to improve the optical properties of silver (EuAgNPs) and gold (EuAuNPs) nanoparticles prepared using the fruit and leaves extracts of Eugenia uniflora $L$.. The nanoparticles were characterized, and their antimicrobial properties were investigated. The fluorescence spectra of silver and gold nanoparticles under different excitation have also been studied.

\section{Materials And Methods}

Silver nitrate $\left(\mathrm{AgNO}_{3}\right)$ and chloroauric acid $\left(\mathrm{HAuCl}_{4}\right)$ were purchased from Sigma-Aldrich. E. uniflora $L$. fruits and leaves were collected from spontaneous germination trees in São Paulo, SP, Brazil. All solutions were prepared with double-distilled water. The $\mathrm{pH}$ was adjusted by the addition of sodium hydroxide $(\mathrm{NaOH})$.

\subsection{Preparation of nanoparticles}

E. uniflora $L$. leaves and fruits (pitanga) of different colors and sizes were washed abundantly with double distilled water and finely chopped. Extracts were prepared with $1.03 \pm 0.03 \mathrm{~g}$ of leaves or fruits in $40 \mathrm{~mL}$ of double-distilled water. Solutions were boiled for 5 minutes.

Leaves extracts or fruits extracts still hot were mixed with $1 \mathrm{mmol}$ of $\mathrm{AgNO}_{3}$ to prepare silver nanoparticles solution (EuAgNPs). The color change was observed due to $\mathrm{AgNO}_{3}$ interaction with extracts and reduction to elemental silver. The $\mathrm{pH}$ of the solution after reaction $(\sim 5.3 \pm 0.3)$.

To prepare gold nanoparticles solution (EuAuNPs), $\mathrm{HAuCl}_{4}(1 \mathrm{mmol})$ was added to the extracts still hot. The formation of nanoparticles was initiated immediately and was completed after $10 \mathrm{~min}$. After the reaction, the suspensions become acidic $(\mathrm{pH} \sim 2.7 \pm 0.3)$.

Nanoparticles properties were improved by the photoreduction process in which silver and gold nanoparticles solutions $(10 \mathrm{~mL}$ ) were illuminated with a 300 Watt Cermax xenon lamp for $1 \mathrm{~min}$. The $\mathrm{pH}$ of the solution after the reaction was adjusted to $\sim 7.0$. Some pictures of the synthesis process are shown in Figure 1.

\subsection{Characterization of nanoparticles}

Shimatzu MultiSpec 1501 spectrophotometer was used in the spectrophotometry analyzes in the UV-vis region. For this measurement, $50 \mathrm{~mL}$ of NPs were diluted in $500 \mathrm{~mL}$ of doubly distilled water, and the measurements were carried out in a $10 \mathrm{~mm}$ optical path quartz cuvette in the range 200 and $800 \mathrm{~nm}$. 
The Fourier transform infrared spectroscopy (FTIR) was obtained with Shimatzu IRPrestige. In this case, $200 \mathrm{ml}$ of the NPs and their extracts were deposited on microscope slides and dried in an oven at 60 degrees. The process was repeated three times. The material deposited on the slides was scraped off to make $\mathrm{KBr}$ pellets.

The stability of the colloidal suspensions was analyzed by Zeta potential measurements using the Zetasizer Nano ZS Malvern apparatus. The analyses were carried out in an electrophoresis cell, where a potential difference was applied to the electrodes. Three measurements were made for each sample.

Transmission electron microscopy images were obtained by the JEM 2100 JEOL microscope.

Fluorescence measurement was recorded on a Fluorolog III Horiba fluorimeter. The fluorescence spectra were accomplished on a $1 \times 1 \mathrm{~cm}$ quartz cell at various excitation wavelengths: $280,300,325,340$, and $410 \mathrm{~nm}$

\subsection{Determination of Antibacterial Efficacy plant extracts and NPs}

The EuAgNPs and EuAuNPs, (table 1) were evaluated against Gram-negative bacteria, namely: Escherichia coli American Type Culture Collection (ATCC) 25922; Escherichia coli 044:H18 EAEC042[35] (clinical isolate); Salmonella Thiphymurium ATCC 14028, Klebsiella pneumoniae ATCC 700603, Pseudomonas aeruginosa ATCC 27853, Gram-positive bacteria Bacillus subtilis ATCC 6633, Staphylococcus aureus ATCC 25923, clinical isolates of methicillin-resistant Staphylococcus aureus (MRSA), Enterococcus faecalis, and against the yeast Candida albicans ATCC 90112 . The clinical strains present the following resistance profile: E. coli 044:H18 EAEC042 - chloramphenicol, tetracycline, and streptomycin, MRSA - amikacin, clindamycin, gentamicin, oxacillin, penicillin, and sulfonamide, and $E$. faecalis - amikacin, clindamycin, gentamicin, oxacillin, penicillin, and erythromycin.

Table 1. Characteristics of samples used in antimicrobial tests.

\begin{tabular}{|ll|}
\hline Name & Method \\
\hline EuAgNP1 & Eu leaves extract $+\mathrm{Xe}(1 \mathrm{~min})+\mathrm{pH} 7.0$ \\
\hline EuAgNP2 & Eu fruit extract $+\mathrm{pH} 7.0$ \\
\hline EuAgNP3 & Eu fruit extract $+\mathrm{Xe}(1 \mathrm{~min})+\mathrm{pH} 7.0$ \\
\hline EuAuNP & Eu fruit extract $+\mathrm{Xe}(1 \mathrm{~min})+\mathrm{pH} 7.0$ \\
\hline
\end{tabular}

The antimicrobial activity of NPs was evaluated in 96-well microtiter plates, according to the CLSI guidelines. Aliquots of $50 \mu \mathrm{L}$ of Mueller-Hinton $(\mathrm{MH})$ broth (bacteria) or Sabouraud (Sab) broth ( $C$. albicans), with bacterial or fungal inoculum adjusted to approximately $10^{6} \mathrm{CFU} / \mathrm{mL}$ was incubated with $50 \mu \mathrm{L}$ of NPs solutions diluted 10 times in MH or Sab broth, resulting in a final volume of $100 \mu \mathrm{l}$ with $10^{4}$ $\mathrm{CFU} /$ well and the final dilution of solutions of 20 times. The plates were incubated at $37^{\circ} \mathrm{C}$ for 20 hours, after which the microbial growth was measured based on optical density (OD) at $595 \mathrm{~nm}$ in an enzyme- 
linked immunosorbent assay (ELISA) reader (Multiskan®EX - Thermo Isher Scientific, EUA). The results were expressed as inhibition percentage of OD compared with the control (microorganisms in the absence of treatment) and expressed as means \pm standard deviation of triplicate assays. The following formula was used to calculate the rate of microbial:

$$
\% \text { Cell inhibition }=\frac{\text { Control at } \left.O D_{595 \mathrm{~nm}}-\text { Test at } O D_{595 \mathrm{~nm}}\right]}{\text { Control at } O D_{595 \mathrm{~nm}}} \times 100
$$

\subsection{Statistical analysis}

Statistics were performed using GraphPad Prism 4.00 software. Differences were considered significant when $P<0.05$, by the Student's $t$ test.

\section{Results}

\subsection{Synthesis and characterizations}

Figure 2a shows the UV-Vis spectra of the obtained extracts. In general, flavonoids show two UV absorption bands, one between $240-280 \mathrm{~nm}$ and the other one around 300-370 nm, which are attributed to conjugations in the B-ring and A-ring, respectively [36]. Leaves extract presents absorption bands around $247 \mathrm{~nm}, 338 \mathrm{~nm}$, probably due to luteolin[37-39], and absorption at $462 \mathrm{~nm}$ due to the presence of carotenoids[40]. Fruits extract presents bands around $248,303,371 \mathrm{~nm}$, probably due to quercetin, absorption at $462 \mathrm{~nm}$, due to the carotenoids, and around $520 \mathrm{~nm}$ due to anthocyanins [16].

Figure $2 \mathrm{~b}$ shows the UV-Vis spectrum of AgNPs synthesized using aqueous extracts. The EuAgNPs produced with leaves extracts without $\mathrm{pH}$ adjustment presented a broad absorbance band with a maximum of around $490 \mathrm{~nm}$, similarly obtained by Dugganaboyana et al. using fruits extract[30]. Surface plasmon resonance (SPR) peak at $420 \mathrm{~nm}$ was observed for EuAgNPs-leaves solution illuminated with Xe lamp for $1 \mathrm{~min}(\mathrm{pH} \sim 7.0$ ). These nanoparticles have sizes of about $17 \mathrm{~nm}$ (TEM image). For EuAgNPs prepared with pitanga extract, it was observed a peak around $444 \mathrm{~nm}$ that shifted to $\sim 422 \mathrm{~nm}$, illuminating the solution with $1 \mathrm{~min}$ of Xe lamp and setting $\mathrm{pH}$ set to 7.0 , which indicated probably reduction in particle size.

The results obtained for the synthesis of EuAuNPs are shown in Figure 2c. The nanoparticles prepared with leaves and fruits extracts present SPR bands around 540 and $534 \mathrm{~nm}$, respectively.

Zeta potential measurements were performed to determine the stability of the suspensions. For EuAgNPs, the more stable particles were obtained with fruit extract irradiated with Xe lamp and pH 7.0 (-21.7mV) (Figure 3). In this case, the polydispersity index (PI) was 0.369. EuAuNPs prepared with pitanga present the followed values:-13.7mV, PI 0.675. 
Figure 4a presents the Fourier transform infrared spectroscopy (FTIR) obtained for E. Uniflora L. leaves extract, EuAgNPs and EuAuNPs prepared with leaves extract, carried out to identify the possible biomolecules responsible for reduction, capping, and efficient stabilization of the $\mathrm{Ag}$ and $\mathrm{Au}$ nanoparticles. Bands around $3400 \mathrm{~cm}^{-1}$, probably related to $-\mathrm{NH}$ and bonded $-\mathrm{OH}$ groups of carboxylic acids $[15,41]$ are observed. Bands in the region $2980-2800 \mathrm{~cm}^{-1}$, indicate the presence of $\mathrm{C}-\mathrm{H}_{2}$ asymmetric and symmetric stretching. Bands in the region 1600 and $1700 \mathrm{~cm}^{-1}$, could be related to $\mathrm{C}=\mathrm{C}$ stretching vibration of aromatic rings [29] [23] [21] and to the vibration of $\mathrm{N}-\mathrm{H}$ of amines, $\mathrm{C}=\mathrm{O}$ of amides, and carboxylic groups [26]; in addition, the band around $1635 \mathrm{~cm}^{-1}$ could be related to flavonoids and amino acids, $\mathrm{v}(\mathrm{C}=\mathrm{O}), \mathrm{v}(\mathrm{C}=\mathrm{C}), \delta a s(\mathrm{~N}-\mathrm{H})$ [24]. The peak observed around $1380 \mathrm{~cm}^{-1}$, indicates that the $\mathrm{C}-\mathrm{H}$ vibration of the different compounds of extracts interacts significantly with EuAgNPs but not with EuAuNPs.

The EuAgNPs prepared with fruits extract with or without photoreduction FTIR spectra can be observed in Figure $4 \mathrm{~b}$. Both present the same functional groups in extract responsible for the bioreduction of $\mathrm{Ag}^{+}$and capping/stabilization of silver nanoparticles, but differences in ratios between bands around 1730 and $1600 \mathrm{~cm}^{-1}$ are observed. The increase in the absorption peaks at $1724 \mathrm{~cm}^{-1}$ is observed for Nps submitted to photoreduction. The peak at $1724 \mathrm{~cm}^{-1}$ corresponds to $\mathrm{C}=0$ stretch (carbonyl). The existence of these bands in the case of plant-mediated AgNPs, clearly demonstrating the involvement of phenolic compounds.

The fluorescence spectra of leaves extracts, EuAgNPs, and EuAuNPs were investigated under different excitation wavelengths (Figure 5). Eu leaves extract (Figure 5a), excited at $340 \mathrm{~nm}$ presents two emission peaks, around $450 \mathrm{~nm}$ and $\sim 515 \mathrm{~nm}$. For EuAgNPs, a shorter emission wavelength was red-shifted (from $320-570 \mathrm{~nm}$ ), along with the increase in excitation wavelength (Figure 5b). For EuAuNPs, as observed in Figure $5 c$, is observed intense fixed bands around 450 and $515 \mathrm{~nm}$ (excitation 325 and $340 \mathrm{~nm}$ ) and a shorter emission wavelength that red-shifts, along with the increase in excitation wavelength. Figure $5 \mathrm{~d}$ shows the dependence between excitation wavelength and narrow high energy peak fluorescence wavelength for EuAgNPs and EuAuNPs.

A theoretical model described by Ding et al. [34] explained plasmon-modulated excitation-dependent fluorescence strongly coupled to gold nanoparticles. By their theory, the fluorophores (without NPs, in their case activated hexadecyltrimethyl ammonium bromide-CTAB*) present long lifetime multilevel states due to the surface states from the functional group. The fluorescence peak $\lambda$ appears at the wavelength,

$$
\bar{\lambda}=\frac{2 \lambda_{\text {exc }} \lambda_{\text {low }}}{\lambda_{\text {exc }}+\lambda_{\text {low }}}(1)[34]
$$

Where $\lambda$ exc is the excitation wavelength and llow is the wavelength of photons emitted from the lowest state relative to the $\mathrm{HOMO}$ of fluorophores. To obtain this equation, the authors have assumed the same 
radiative/nonradiative rate and the same spectral width for all intermediate states. This equation demonstrates that the fluorescence peak wavelength increases with the excitation wavelength[34].

The red-shifted emission peaks for EuAg and EuAuNPs observed in Figure $5 \mathrm{~b}$ and $\mathrm{c}$ were plotted in function for the excitation wavelengths $280,300,325$, and $340 \mathrm{~nm}$ and presented in Figure $5 \mathrm{~d}$. The fit curve (red line) plotted using equation (1) indicated that the results agree well with this equation. From the obtained parameter " $\mathrm{A}$ " it is possible to calculate the frequency of photons emitted from the lowest state with frequency $\omega_{\text {low }}$ relative to the HOMO of excitation-dependent fluorophores.

\subsection{Antimicrobial tests}

The antimicrobial activity of EuAgNPs, and EuAuNPs was tested using the broth microdilution assay, which provides quantitative data on inhibition efficacy, and results are presented in Figure 6 for tested NPs described in Table 1. The results demonstrated that most of the microbial species, including $C$. albicans, showed high inhibition percentual ( $>90 \%$ ) when exposed to EuAgNPs prepared with fruit extract and photoreduction (Figure 6) except for E. faecalis (54\%). In contrast, EuAgNPs prepared with leaves extract and photoreduction showed more inhibition of $S$. aureus, methicillin-resistant $S$. aureus (MRSA), $E$. faecalis than EuAgNPs prepared with fruit extract and photoreduction.

The results indicated high inhibition percentual of Gram-positive, Gram-negative bacteria and yeast treated with EuAgNps (33.00\% to $100 \%$, with a mean of $89.95 \% \pm 19.78 \%$ ), in comparison with EuAuNPs treatment $(P<0.05)$. The antimicrobial effect of EuAuNPs ranged from $0 \%-71.27 \%$, presenting a mean of $32.39 \% \pm 18.00$. EuAg Fruit inhibited $53.71 \%$ to $100.0 \%$ (with a mean of $95.12 \% \pm 10.29 \%$ ) of microorganisms, whereas EuAu Fruit inhibited $19.85 \%$ to $71.27 \%$ (with a mean of $32.39 \% \pm 18.00 \%$ ). EuAg Fruit without $X e$ and Ag Fruit exposed to Xe did not possess a significant $(P>0.05)$ difference.

All treatments tested exhibited high inhibition percentual of B. subtilis, especially EuAgNPs $(98.83 \%$ 99.47\%), whereas, with EuAuNPs, it reached $66.23 \%$ to $75.88 \%$. On the other hand, Au Fruit $1 \mathrm{Xe} \mathrm{pH} 7.0$ was not effective against $K$. pneumoniae ATCC 700603.

\section{Discussion}

Chemically, phenolic substances present in plant extracts are defined as those that have in their structure one (or more) aromatic rings with one or more hydroxyl substitutes [42]. These substances have variable structures and are therefore multifunctional. Phenolic metabolites include phenolic acids, flavonoids, simple phenolics, phenylpropanoids, coumarins, tannins, and tocopherols[16].

In general, phenolic substances are potent antioxidants, acting by several mechanisms such as electron donation and interruption of the chain of oxidation reactions [42]. In addition to their antioxidant capacity, phenolic substances, mainly phenolic acids, flavonoids, and tannins, have other health-beneficial properties such as anticancer, antimicrobial, antiallergic, hepatoprotective, antithrombotic, antiviral, 
vasodilator, antimutagenic and anti-inflammatory activity since many of these biological functions have been correlated with their antioxidant capacity.

The absorption spectrum for the aqueous extracts of $E$. uniflora $L$. (Figure 2a) shows absorbance peaks in the ultraviolet region at wavelengths compatible with the presence of phenolic metabolites[43]. Absorption bands around $247 \mathrm{~nm}, 338 \mathrm{~nm}$ (flavonoids probably luteolin), and a peak around $462 \mathrm{~nm}$ probably due to carotenoids were observed for leaves extracts and bands around $248,303,371 \mathrm{~nm}$, that can be attributed to flavonoids as quercetin[44], were observed for fruits extracts.

The use of plant extracts for nanoparticles synthesis is a straightforward green method and economically viable[45]. There are several works in the literature evidencing good results of synthesis and antimicrobial activities of nanoparticles prepared with plants extracts[46-49]. Here, EuNPs with leaves and fruits extracts are associated with the photoreduction method and $\mathrm{pH}$ control.

E. uniflora $L$. phytochemicals as saponin, tannins, phenolic compounds, and flavonoids [23-25, 50, 51], interact with $\mathrm{AgNO}_{3}$ or $\mathrm{HAuCl}_{4}$ that are reduced to elemental silver or gold, respectively. Biosynthesis probably involves quercetin [52] and anthocyanins in fruits extract and luteolin[53] in leaves extract.

The results showed that Xenon lamp irradiation and $\mathrm{pH}$ adjustment improve optical properties of $E$. uniflora $L$. nanoparticles. The stabilization of NPs can be divided into three different categories, including steric, electrostatic, and unification of steric and electrostatic stabilization[54]. Although electrostatic stabilization is easier to maintain in colloidal media, due to strong forces of interactions between oppositely charged ions, it is impossible to separate agglomerated particles. So immediately after mix plants extracts and silver nitrate or $\mathrm{HAuCl}_{4}$, the SPR bands are wide, indicating the presence of agglomerates. Electrostatic stabilization is regulated by $\mathrm{pH}$ adjustment, and the SPR bands become narrowed, indicating monodispersed nanoparticles. Steric stabilization is a thermodynamic stabilization method; therefore, particles can be redispersed. This stabilization can be achieved using ionic surfactants but also the photoreduction method. Photoreduction offers steric repulsion within nanoparticles, thus preventing the agglomeration and giving rise to a mutual stabilization system[55].

The Zeta potential results, presented in Figure 3, indicated that the photoreduction process can improve the stability of EuNPs. The high zeta potential values mean that EuNPs are highly stable due to the presence of a high surface charge, which prevents agglomeration.

The increase in the absorption peaks at $3878 \mathrm{~cm}^{-1}$ is observed for EuAgNps prepared with fruits extract and photoreduction (Figure 4), indicating that $\mathrm{C}-\mathrm{H}$ vibration of the different compounds of extracts interacts significantly with EuAgNPs. The peak around $1727 \mathrm{~cm}^{-1}$, due to $\mathrm{C}=0$ stretch clearly in EuAgNPs prepared with fruits extract, indicates the involvement of carbonyl functional group in silver reduction and stabilization, probably attributed to the presence of quercetin in the fruits extract.

The fluorescence spectra of leaves extracts, EuAgNPs, and EuAuNPs were investigated under different excitation wavelengths (Figure 5). The changes in fluorescence behaviors showed in Figure 5 are induced 
by several fluorescence mechanisms. Figure 5a show emission observed from extract fluorophores due basically to flavonoids molecules at around 450 and $515 \mathrm{~nm}$ (excitation $340 \mathrm{~nm}$ ) [39, 56]. In Figure 5b is observed that EuAgNPs have two emission regions, a narrow emission peak around $320-380 \mathrm{~nm}$, and a broad emission band around $380-500 \mathrm{~nm}$. We speculated that the narrow emission is attributed to electron-hole recombination or quantum size effect, while the broad emission is attributed to surface fluorophores (flavonoids) [57].

Figure $5 \mathrm{c}$ presents the fluorescence spectra of EuAuNPs with different excitation wavelengths from 280 to $410 \mathrm{~nm}$. The narrow emissions observed for EuAuNPs are attributed to recombination of sp electrons with holes in the $d$ band[58], and the broad fixed are attributed to LSP- enhanced radiative emission. In the presence of EuAuNPs, the surface plasmon resonance leads to the local field enhancement. EuAuNPs emission intensity around $450 \mathrm{~nm}$ enhanced 4 times in comparison to the Eu extract emission. Figure 5d clearly shows that the position of high-energy peak red-shifts as the excitation wavelength increases for both EuAg and EuAuNPs, and the theoretical model proposed by Ding et al. [34] can describe excitationdependent fluorescence spectra of extract fluorophores with metallic nanoparticles.

Recently, metal-enhanced fluorescence has led to new developments and applications by improving the fluorescence intensity of various materials. When the fluorophores or emitters are placed in proximity but to an optimum distance from silver or gold nanoparticles, they are benefitted from the additional plasmon-enhanced optical fields. The observed enhanced fluorescence intensity is due to the local field enhancement associated with the excitation of LSPRs in the metal nanostructures. The plasmonic nanoparticle here serves as a transmitting optical antenna to transfer the near field to the far-field at the fluorescence wavelength[59].

According to Sobeh et al., the essential oil extracted from E. uniflora L. presents antimicrobial activity against Staphylococcus aureus, Staphylococcus epidermidis, Bacillus licheniformis, Bacillus subtilis, Enterococcus faecalis, Escherichia coli, Klebsiella pneumoniae, Pseudomonas aeruginosa, Candida parapsilosis and Candida albicans[60]. In the present paper, we obtained the antimicrobial activities of silver and gold nanoparticles synthesized with E. uniflora L. extracts.

The obtained results (Figure 6) indicated that low concentrations of synthesized EuAgNPs (50 $\mu$ L of NPs solutions diluted 10 times) showed inhibitory activity against Gram-positive and Gram-negative bacteria. Higher inhibition was obtained against spherical bacteria as S. Thiphymurium, B. subtilis, S. aureus. E. faecalis, and Candida albicans. EuAgNPs prepared with fruit extract are more effective than those prepared with leaf extract. All tested bacteria treated with EuAgNPs prepared with fruit extract show inhibition $>90 \%$.

The solutions prepared with controlled $\mathrm{pH}$ and $\mathrm{Xe}$ illumination presented excellent results for all tested microorganisms except, Gram-negative bacteria E. coli, P. aeruginosa K. pneumoniae, and C. albicans, whose have a thicker peptidoglycan layer in their cell wall. Probably the best results could be obtained with these nanoparticles in lower concentrations. 
EuAuNPs presented low antimicrobial inhibition, but $B$. subtilis treated with AuNPs presented inhibition $>70 \%$.

The results showed that EuAgNPs exhibited superior antimicrobial activity when compared to EuAuNPs, against tested strains. These nanoparticles could be impregnated in the equipment of individual protection to improve reducing the bacterial growth of the device and promoting the reduction of hospitalacquired infections. Another possible application is suppressing both viral (as COVID-19) and bacterial respiratory infections by inhalation delivery.

Metal nanoparticles can penetrate the bacterial cell and interact with sulfur and phosphorous bases from DNA molecules, decreasing the capacity for cell replication. Another mechanism of the inhibitory action is the induction of oxidative stress due to the generation of the reactive oxygen species (ROS), including free radicals. They are capable of damaging the cell membrane, making it porous, denaturing proteins, and inhibit cellular respiratory enzymes, leading to cell death(Maillard and Hartemann 2013, Franci et al. 2015, Baptista et al. 2018). EuNPs may be employing one or more of these mechanisms to inhibit microbial growth.

The facile synthesis and excellent properties, such as good stability and low polydispersity, guarantee several essential applications in biology and medicine to the synthesized nanoparticles.

\section{Conclusions}

The EuAgNPs were successfully prepared using the aqueous extract of leaves and fruits as a reducing agent source. The photo-induced synthesis has provided a clean and convenient way to improve the optical properties of nanoparticles. The outcome of the present study showed that $E$. uniflora $L$. extracts are suitable for reducing agents to synthesize silver nanoparticles with Zeta potential around $-20 \mathrm{mV}$ and polydispersity $\sim 0.3$. To the best of our knowledge, first-time plant-mediate metallic nanoparticles have been used to study MEF under aqueous conditions. With the addition of suitable EuAuNPs, the fluorescence intensity of the flavonoids was found to be increased $\sim 4$-fold. The comparisons of

antibacterial activity of the EuNPs further confirm the antibiotic efficiency of the green-synthesized EuNPs for the development of novel antibacterial agents for treatment against Gram-negative and Gram-positive pathogens.

\section{Declarations}

\section{Data Availability}

The authors declare that the data supporting the findings of this study are available in the article.

\section{Funding}


This work was supported by São Paulo Research Foundation -Fapesp grants 2017/23686-6 (Lilia Coronato Courrol) and 2019/13291-0 (Marcia Regina Franzolin).

\section{Affiliations}

Instituto de Ciências Ambientais, Químicas e Farmacêuticas, Departamento de Física, Universidade Federal de São Paulo, Diadema, São Paulo, Brazil

Lilia Coronato Courrol, Karina de Oliveira Gonçalves

\section{Laboratório de Bacteriologia, Instituto Butantan, São Paulo, SP, Brazil}

Marcia Regina Franzolin and Daniella dos Santos Courrol

\section{Contributions}

LCC and MRF designed the study and carried out the data analysis and interpretation of the results. MRF and DSC performed antimicrobial studies. All authors drafted the manuscript authors to read and approved the final manuscript.

\section{Ethics declarations}

Not applicable

\section{Competing Interests}

The authors declare that there are no conflicts of interest.

\section{Ethics Approval}

For this type of study, the ethical approval was not required, because this study does not involve cell or animal manipulation.

\section{References}

1. Ahmad H, Rajagopal K, Shah AH. The Green route of Silver nanotechnology: Phytosynthesis and applications. International Journal of Nano Dimension. 2016;7(2):97-108. doi: 10.7508/ijnd.2016.02.001.

2. Ahmad S, Munir S, Zeb N, Ullah A, Khan B, Ali J, et al. Green nanotechnology: a review on green synthesis of silver nanoparticles - an ecofriendly approach. International Journal of Nanomedicine. 2019;14:5087-107. doi: 10.2147/ijn.s200254.

3. Benelli G, Kadaikunnan S, Alharbi NS, Govindarajan M. Biophysical characterization of Acacia caesiafabricated silver nanoparticles: effectiveness on mosquito vectors of public health relevance and impact 
on non-target aquatic biocontrol agents. Environmental Science and Pollution Research. 2018;25(11):10228-42. doi: 10.1007/s11356-017-8482-y.

4. Biswas A, Vanlalveni C, Adhikari PP, Lalfakzuala R, Rokhum L. Green biosynthesis, characterisation and antimicrobial activities of silver nanoparticles using fruit extract of Solanum viarum. let Nanobiotechnology. 2018;12(7):933-8. doi: 10.1049/iet-nbt.2018.0050.

5. Das P, Karankar VS. New avenues of controlling microbial infections through anti-microbial and antibiofilm potentials of green mono-and multi-metallic nanoparticles: A review. Journal of Microbiological Methods. 2019;167. doi: 10.1016/j.mimet.2019.105766.

6. De Souza CD, Nogueira BR, Rostelato M. Review of the methodologies used in the synthesis gold nanoparticles by chemical reduction. Journal of Alloys and Compounds. 2019;798:714-40. doi: 10.1016/j.jallcom.2019.05.153.

7. Ghaffari-Moghaddam M, Hadi-Dabanlou R, Khajeh M, Rakhshanipour M, Shameli K. Green synthesis of silver nanoparticles using plant extracts. Korean Journal of Chemical Engineering. 2014;31(4):548-57. doi: 10.1007/s11814-014-0014-6.

8. Hamelian M, Hemmati S, Varmira K, Veisi H. Green synthesis, antibacterial, antioxidant and cytotoxic effect of gold nanoparticles using Pistacia Atlantica extract. Journal of the Taiwan Institute of Chemical Engineers. 2018;93:21-30. doi: 10.1016/j.jtice.2018.07.018.

9. Iravani S. Green synthesis of metal nanoparticles using plants. Green Chemistry. 2011;13(10):2638-50. doi: $10.1039 / \mathrm{c} 1 \mathrm{gc} 15386 \mathrm{~b}$.

10. Kanchi S, Kumar G, Lo AY, Tseng CM, Chen SK, Lin CY, et al. Exploitation of de-oiled jatropha waste for gold nanoparticles synthesis: A green approach. Arabian Journal of Chemistry. 2018;11(2):247-55. doi: 10.1016/j.arabjc.2014.08.006.

11. Kratosova G, Holisova V, Konvickova Z, Ingle AP, Gaikwad S, Skrlova K, et al. From biotechnology principles to functional and low-cost metallic bionanocatalysts. Biotechnology Advances. 2019;37(1):154-76. doi: 10.1016/j.biotechadv.2018.11.012.

12. Courrol DD, Lopes CRB, Cordeiro TD, Franzolin MR, Vieira ND, Samad RE, et al. Optical properties and antimicrobial effects of silver nanoparticles synthesized by femtosecond laser photoreduction. Optics and Laser Technology. 2018;103:233-8. doi: 10.1016/j.optlastec.2018.01.044.

13. Kshirsagar P, Sangaru SS, Malvindi MA, Martiradonna L, Cingolani R, Pompa PP. Synthesis of highly stable silver nanoparticles by photoreduction and their size fractionation by phase transfer method. Colloids and Surfaces a-Physicochemical and Engineering Aspects. 2011;392(1):264-70. doi: 10.1016/j.colsurfa.2011.10.003. 
14. Sakamoto M, Fujistuka M, Majima T. Light as a construction tool of metal nanoparticles: Synthesis and mechanism. Journal of Photochemistry and Photobiology C-Photochemistry Reviews. 2009;10(1):3356. doi: 10.1016/j.jphotochemrev.2008.11.002.

15. Lopes CRB, Courrol LC. Green synthesis of silver nanoparticles with extract of Mimusops coriacea and light. Journal of Luminescence. 2018;199:183-7. doi: 10.1016/j.jlumin.2018.03.030.

16. Bailão EF, Devilla IA, da Conceição EC, Borges LL. Bioactive Compounds Found in Brazilian Cerrado Fruits. Int J Mol Sci. 2015;16(10):23760-83. doi: 10.3390/ijms161023760.

17. Schapoval EE, Silveira SM, Miranda ML, Alice CB, Henriques AT. Evaluation of some pharmacological activities of Eugenia uniflora L. J Ethnopharmacol. 1994;44(3):137-42. doi: 10.1016/03788741(94)01178-8.

18. Denardin CC, Parisi MM, Martins LA, Terra SR, Borojevic R, Vizzotto M, et al. Antiproliferative and cytotoxic effects of purple pitanga (Eugenia uniflora L.) extract on activated hepatic stellate cells. Cell Biochem Funct. 2014;32(1):16-23. doi: 10.1002/cbf.2965.

19. Pereira NLF, Aquino PEA, Júnior JGAS, Cristo JS, Vieira Filho MA, Moura FF, et al. In vitro evaluation of the antibacterial potential and modification of antibiotic activity of the Eugenia uniflora L. essential oil in association with led lights. Microb Pathog. 2017;110:512-8. doi: 10.1016/j.micpath.2017.07.048.

20. Rodrigues KA, Amorim LV, de Oliveira JM, Dias CN, Moraes DF, Andrade EH, et al. Eugenia uniflora L. Essential Oil as a Potential Anti-Leishmania Agent: Effects on Leishmania amazonensis and Possible Mechanisms of Action. Evid Based Complement Alternat Med. 2013;2013:279726. doi:

$10.1155 / 2013 / 279726$.

21. Santos KK, Matias EF, Tintino SR, Souza CE, Braga MF, Guedes GM, et al. Enhancement of the antifungal activity of antimicrobial drugs by Eugenia uniflora L. J Med Food. 2013;16(7):669-71. doi: 10.1089/jmf.2012.0245.

22. Silva NC, Barbosa L, Seito LN, Fernandes A. Antimicrobial activity and phytochemical analysis of crude extracts and essential oils from medicinal plants. Nat Prod Res. 2012;26(16):1510-4. doi: 10.1080/14786419.2011.564582.

23. Victoria FN, Lenardão EJ, Savegnago L, Perin G, Jacob RG, Alves D, et al. Essential oil of the leaves of Eugenia uniflora L.: antioxidant and antimicrobial properties. Food Chem Toxicol. 2012;50(8):2668-74. doi: 10.1016/j.fct.2012.05.002.

24. Figueiredo PLB, Pinto LC, da Costa JS, da Silva ARC, Mourão RHV, Montenegro RC, et al. Composition, antioxidant capacity and cytotoxic activity of Eugenia uniflora L. chemotype-oils from the Amazon. J Ethnopharmacol. 2019;232:30-8. doi: 10.1016/j.jep.2018.12.011. 
25. Lago JH, Souza ED, Mariane B, Pascon R, Vallim MA, Martins RC, et al. Chemical and biological evaluation of essential oils from two species of Myrtaceae - Eugenia uniflora L. and Plinia trunciflora (O. Berg) Kausel. Molecules. 2011;16(12):9827-37. doi: 10.3390/molecules16129827.

26. Porcu OM, Rodriguez-Amaya DB. Variation in the carotenoid composition of the lycopene-rich Brazilian fruit Eugenia uniflora L. Plant Foods Hum Nutr. 2008;63(4):195-9. doi: 10.1007/s11130-0080085-9.

27. Liu C, Cai D, Zhang L, Tang W, Yan R, Guo H, et al. Identification of hydrolyzable tannins (punicalagin, punicalin and geraniin) as novel inhibitors of hepatitis B virus covalently closed circular DNA. Antiviral Res. 2016;134:97-107. doi: 10.1016/j.antiviral.2016.08.026.

28. Liu S, Chen R, Hagedorn CH. Tannic Acid Inhibits Hepatitis C Virus Entry into Huh7.5 Cells. PLoS One. 2015;10(7):e0131358. doi: 10.1371/journal.pone.0131358.

29. Priya S, Kumar NS, Hemalatha S. Antiviral phytocompounds target envelop protein to control Zika virus. Comput Biol Chem. 2018;77:402-12. doi: 10.1016/j.compbiolchem.2018.08.008.

30. Al Guru Kumar, Sharanya Raj NL RK, Nagendra KS. Novel biogenic synthesis of AgNPs from seed extract of Eugenia uniflora L.: in vitro assessment of theirantioxidant, antimicrobial and cytotoxic potential. . Int Res J Pharm. 2017;8(11):109-14

31. Cao SH, Cai WP, Liu Q, Li YQ. Surface Plasmon-Coupled Emission: What Can Directional Fluorescence Bring to the Analytical Sciences? Annual Review of Analytical Chemistry, Vol 5. 2012;5:317-36. doi: 10.1146/annurev-anchem-062011-143208.

32. Pawar S, Bhattacharya A, Nag A. Metal-Enhanced Fluorescence Study in Aqueous Medium by Coupling Gold Nanoparticles and Fluorophores Using a Bilayer Vesicle Platform. Acs Omega. 2019;4(3):5983-90. doi: 10.1021/acsomega.9b00036.

33. Ou XW, Liu YQ, Zhang MX, Hua L, Zhan SS. Plasmonic gold nanostructures for biosensing and bioimaging. Microchimica Acta. 2021;188(9):15. doi: 10.1007/s00604-021-04964-1.

34. Ding SJ, Nan F, Liu XL, Hao ZH, Zhou L, Zeng J, et al. Plasmon-Modulated Excitation-Dependent Fluorescence from Activated CTAB Molecules Strongly Coupled to Gold Nanoparticles. Scientific Reports. 2017;7. doi: 10.1038/srep43282.

35. Nataro JP, Baldini MM, Kaper JB, Black RE, Bravo N, Levine MM. DETECTION OF AN ADHERENCE FACTOR OF ENTEROPATHOGENIC ESCHERICHIA-COLI WITH A DNA PROBE. Journal of Infectious Diseases. 1985;152(3):560-5. doi: 10.1093/infdis/152.3.560.

36. Skoko S, Ambrosetti M, Giovannini T, Cappelli C. Simulating Absorption Spectra of Flavonoids in Aqueous Solution: A Polarizable QM/MM Study. Molecules. 2020;25(24). doi:

10.3390/molecules25245853. 
37. da Cunha FAB, Waczuk EP, Duarte AE, Barros LM, Elekofehinti OO, Matias EFF, et al. Cytotoxic and antioxidative potentials of ethanolic extract of Eugenia uniflora L. (Myrtaceae) leaves on human blood cells. Biomedicine \& Pharmacotherapy. 2016;84:614-21. doi: 10.1016/j.biopha.2016.09.089.

38. Denni M, Mammen D. A critical evaluation on the reliability of two aluminum chloride chelation methods for quantification of flavonoids. Food Chemistry. 2012;135(3):1365-8. doi:

10.1016/j.foodchem.2012.05.109.

39. Amat A, Clementi C, De Angelis F, Sgamellotti A, Fantacci S. Absorption and Emission of the Apigenin and Luteolin Flavonoids: A TDDFT Investigation. Journal of Physical Chemistry A. 2009;113(52):1511826. doi: $10.1021 /$ jp9052538.

40. Polyakov NE, Konovalov VV, Leshina TV, Luzina OA, Salakhutdinov NF, Konovalova TA, et al. Oneelectron transfer product of quinone addition to carotenoids EPR and optical absorption studies. Journal of Photochemistry and Photobiology a-Chemistry. 2001;141(2-3):117-26. doi: 10.1016/s10106030(01)00429-4.

41. Patle TK. Phytochemical screening and determination of phenolics and flavonoids in Dillenia pentagyna using UV-vis and FTIR spectroscopy. In: University RKPRSUSUPRSURJPRSURCPRS, editor.

42. Fu L, Xu B-T, Xu X-R, Gan R-Y, Zhang Y, Xia E-Q, et al. Antioxidant capacities and total phenolic contents of 62 fruits. Food Chemistry. 2011;129(2):345-50. doi: 10.1016/j.foodchem.2011.04.079.

43. Patle TK, Shrivas K, Kurrey R, Upadhyay S, Jangde R, Chauhan R. Phytochemical screening and determination of phenolics and flavonoids in Dillenia pentagyna using UV-vis and FTIR spectroscopy. Spectrochimica Acta Part a-Molecular and Biomolecular Spectroscopy. 2020;242. doi:

10.1016/j.saa.2020.118717.

44. Das K, Khan AA, Gowthami V, Sharma V, Ahmed SY. Mitigation of dermal auto immune disease through combined action of natural constituents: An advantageous over allopathic medicines. Annals of Phytomedicine-an International Journal. 2020;9(1):162-70. doi: 10.21276/ap.2020.9.1.21.

45. Makarov VV, Love AJ, Sinitsyna OV, Makarova SS, Yaminsky IV, Taliansky ME, et al. "Green" Nanotechnologies: Synthesis of Metal Nanoparticles Using Plants. Acta Naturae. 2014;6(1):35-44. doi: 10.32607/20758251-2014-6-1-35-44.

46. Gardea-Torresdey JL, Gomez E, Peralta-Videa JR, Parsons JG, Troiani H, Jose-Yacaman M. Alfalfa sprouts: A natural source for the synthesis of silver nanoparticles. Langmuir. 2003;19(4):1357-61. doi: $10.1021 / \mathrm{la0} 20835 \mathrm{i}$.

47. Hussain M, Raja NI, Iqbal M, Aslam S. Applications of Plant Flavonoids in the Green Synthesis of Colloidal Silver Nanoparticles and Impacts on Human Health. Iranian Journal of Science and Technology Transaction a-Science. 2019;43(A3):1381-92. doi: 10.1007/s40995-017-0431-6. 
48. Akhtar MS, Panwar J, Yun YS. Biogenic Synthesis of Metallic Nanoparticles by Plant Extracts. Acs Sustainable Chemistry \& Engineering. 2013;1(6):591-602. doi: 10.1021/sc300118u.

49. Sintubin L, Verstraete W, Boon N. Biologically produced nanosilver: Current state and future perspectives. Biotechnology and Bioengineering. 2012;109(10):2422-36. doi: 10.1002/bit.24570.

50. Dos Santos JFS, Rocha JE, Bezerra CF, do Nascimento Silva MK, de Matos YMLS, de Freitas TS, et al. Chemical composition, antifungal activity and potential anti-virulence evaluation of the Eugenia uniflora essential oil against Candida spp. Food Chem. 2018;261:233-9. doi: 10.1016/j.foodchem.2018.04.015.

51. Einbond LS, Reynertson KA, Luo XD, Basile MJ, Kennelly EJ. Anthocyanin antioxidants from edible fruits. Food Chemistry. 2004;84(1):23-8. doi: 10.1016/s0308-8146(03)00162-6.

52. Tasca F, Antiochia R. Biocide Activity of Green Quercetin-Mediated Synthesized Silver Nanoparticles. Nanomaterials. 2020;10(5). doi: 10.3390/nano10050909.

53. Qing WX, Wang Y, Li X, Lu MH, Liu XH. Facile synthesis of mPEG-luteolin-capped silver nanoparticles with antimicrobial activity and cytotoxicity to neuroblastoma SK-N-SH cells. Colloids and Surfaces BBiointerfaces. 2017;160:390-4. doi: 10.1016/j.colsurfb.2017.09.048.

54. Amina SJ, Guo B. A Review on the Synthesis and Functionalization of Gold Nanoparticles as a Drug Delivery Vehicle. International Journal of Nanomedicine. 2020;15:9823-57. doi: 10.2147/ijn.s279094.

55. Lewis FD. STERIC EFFECTS IN PHOTOREDUCTION OF ARYL ALKYL KETONES. Tetrahedron Letters. 1970(16):1373-\&.

56. Chaudhuri S, Sengupta B, Taylor J, Pahari BP, Sengupta PK. Interactions of Dietary Flavonoids with Proteins: Insights from Fluorescence Spectroscopy and Other Related Biophysical Studies. Current Drug Metabolism. 2013;14(4):491-503. doi: 10.2174/1389200211314040011.

57. Zhu SJ, Zhang JH, Tang SJ, Qiao CY, Wang L, Wang HY, et al. Surface Chemistry Routes to Modulate the Photoluminescence of Graphene Quantum Dots: From Fluorescence Mechanism to Up-Conversion Bioimaging Applications. Advanced Functional Materials. 2012;22(22):4732-40. doi: 10.1002/adfm.201201499.

58. Parang Z, Keshavarz A, Farahi S, Elahi SM, Ghoranneviss M, Parhoodeh S. Fluorescence emission spectra of silver and silver/cobalt nanoparticles. Scientia Iranica. 2012;19(3):943-7. doi: 10.1016/j.scient.2012.02.026.

59. Ghosh RR, Dhawan A. Extremely large near-field enhancements in the vicinity of plasmonic nanoantennas on top of bull's eye structures exhibiting the extra ordinary transmission of light. Osa Continuum. 2021;4(1):193-211. doi: 10.1364/osac.396029. 
60. Sobeh M, Braun MS, Krstin S, Youssef FS, Ashour ML, Wink M. Chemical Profiling of the Essential Oils of Syzygium aqueum, Syzygium samarangense and Eugenia uniflora and Their Discrimination Using Chemometric Analysis. Chemistry \& Biodiversity. 2016;13(11):1537-50. doi: 10.1002/cbdv.201600089.

\section{Figures}

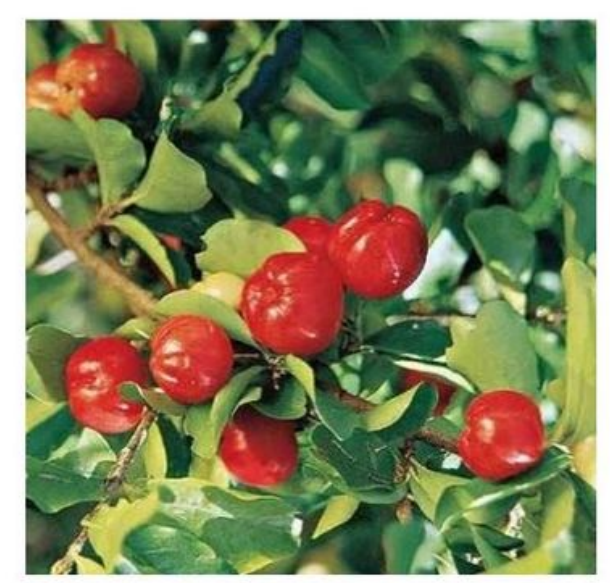

a)

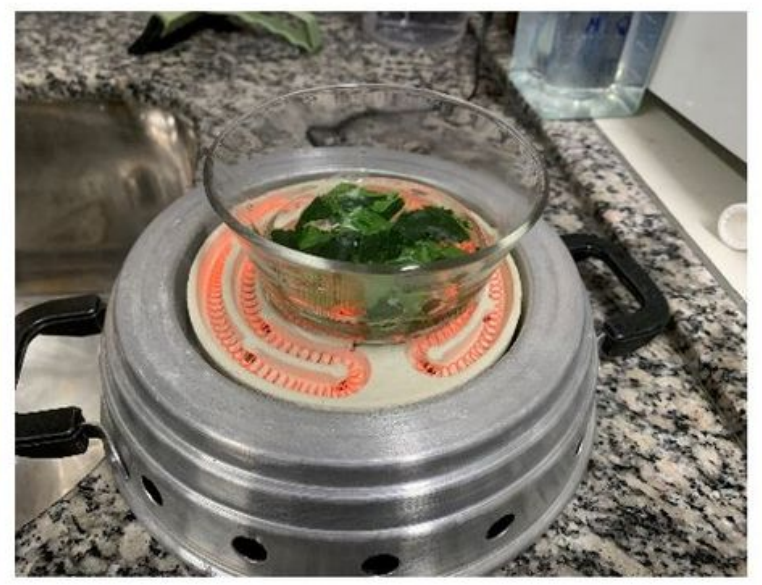

b)

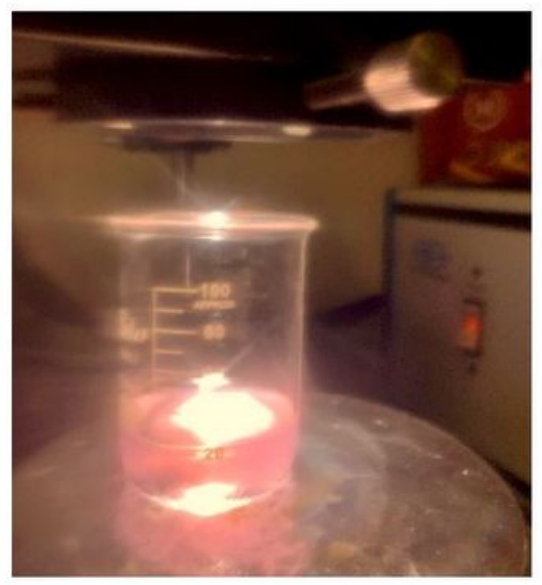

c)

Figure 1

a) E. uniflora L. (pitangueira), b) Leaves extract preparation, c) Photoreduction.

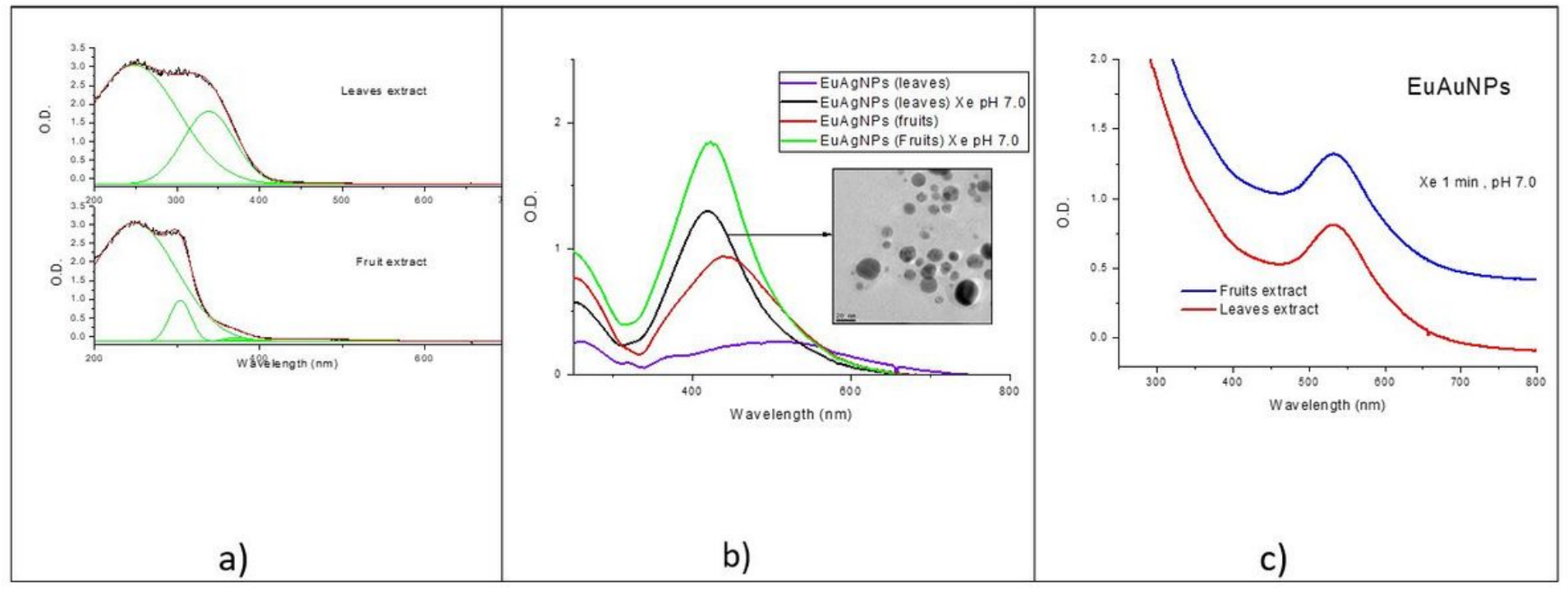

Figure 2

UV-Vis absorbance spectra of a) E. uniflora L. leaves and fruits extracts; b) synthesized EuAgNPs prepared with leaf extract, pitanga extract, and Xenon irradiation for $1 \mathrm{~min}$ and $\mathrm{pH} \sim 7.0$ of leaves extract (figure inside TEM) and pitanga extract. c) UV-Vis absorbance spectra of E. uniflora fruits and leaves extracts, EuAuNPs+ Xe (1 min) $+\mathrm{pH} 7.0$. 
Zeta Potential Dis tribution

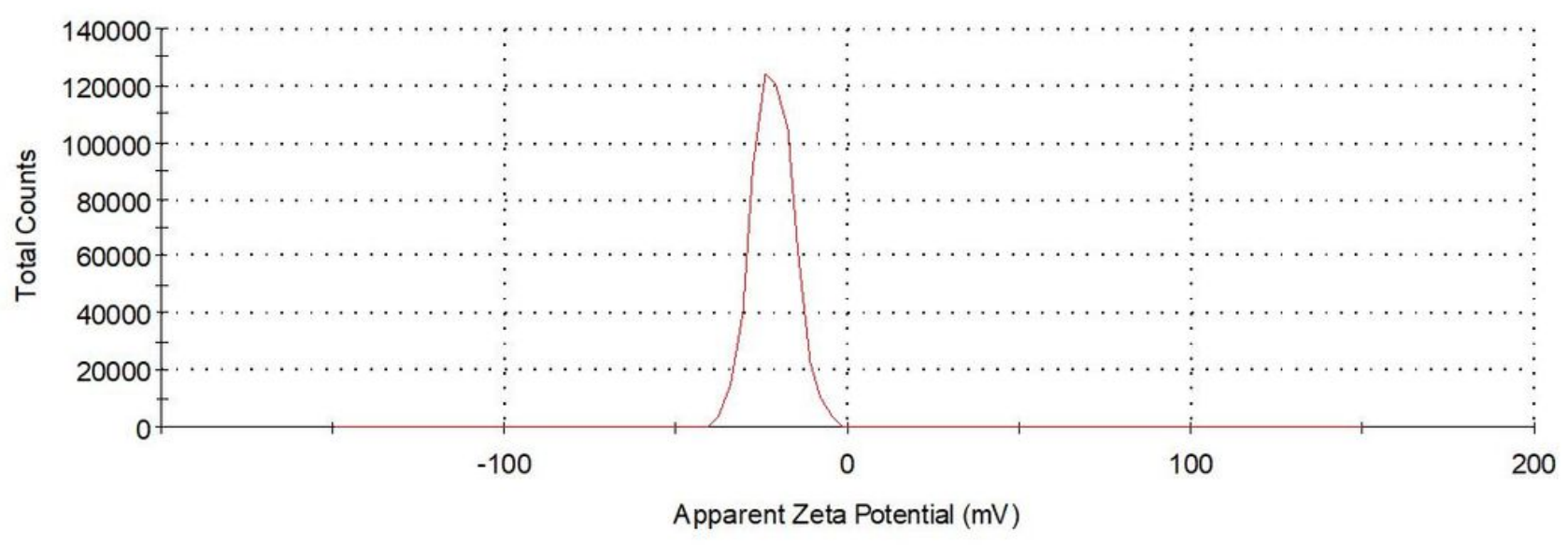

Record 3: 43

\section{Figure 3}

Zeta potential analysis of synthesized EuAgNPs using E. uniflora fruit extract, Xe illumination and pH 7.0. 


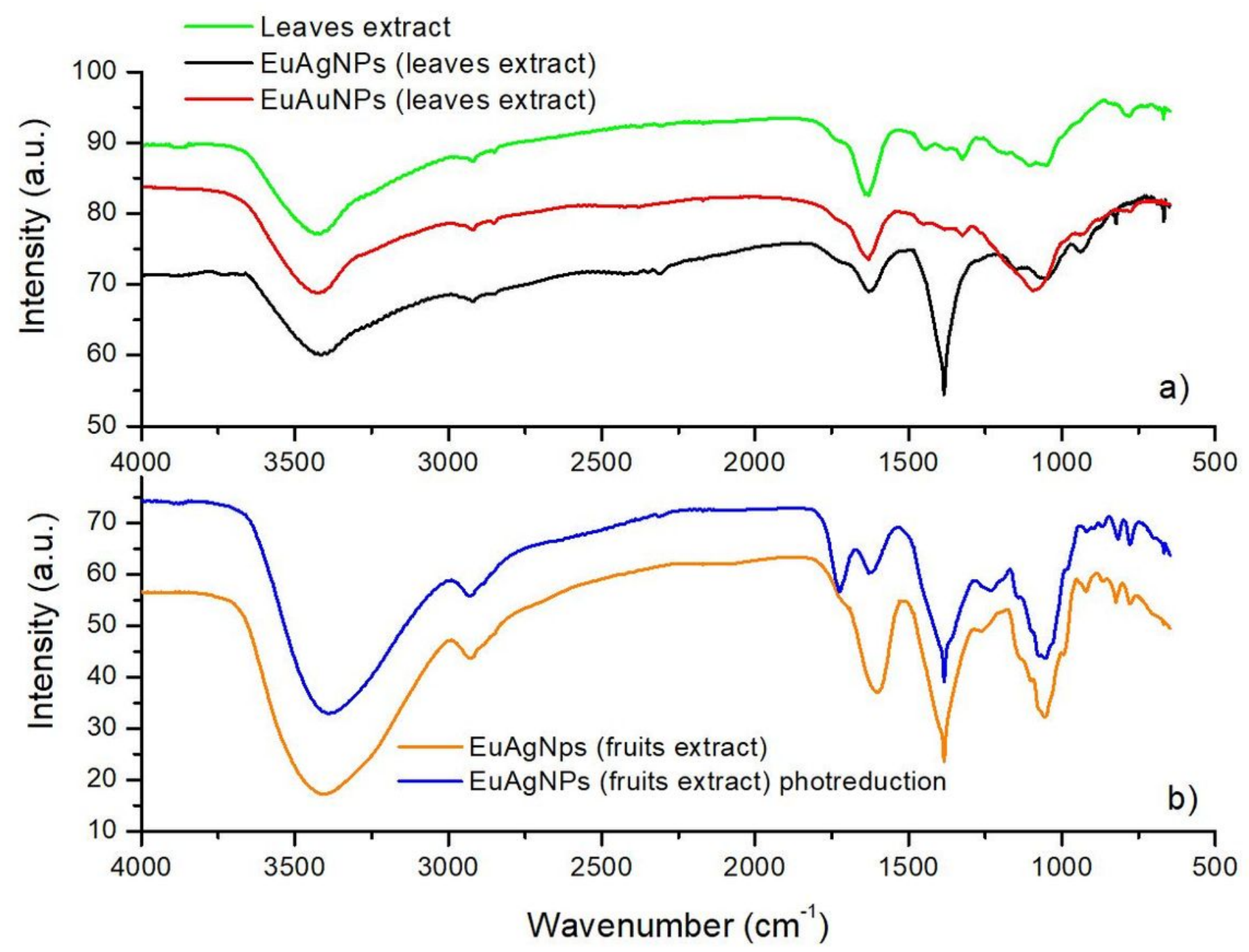

Figure 4

a) FTIR spectra of E. uniflora L. leaves extract, and EuAgNPs and EuAuNPs prepared with leaves extract.

(b) FTIR spectra of EuAgNPs (fruits extract) prepared without and with photoreduction process. 
a)
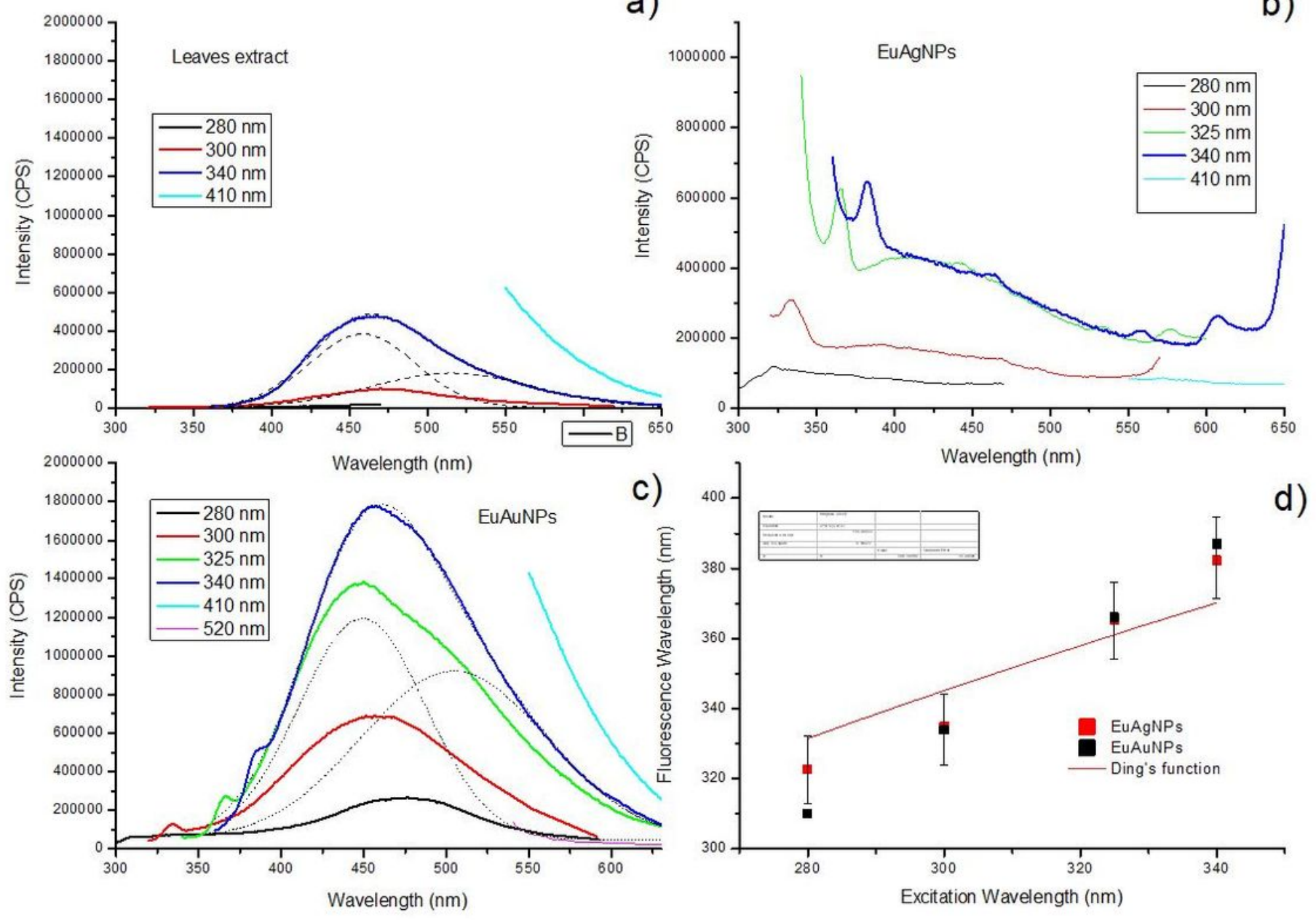

b)

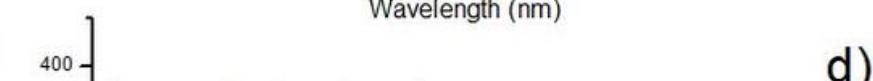

\section{Figure 5}

Fluorescence spectra were obtained for excitations from 280 to $410 \mathrm{~nm}$ for a) E. uniflora L. leaves extracts; b) synthesized EuAgNPs prepared with leaves extract, Xenon irradiation for 1 min and $\mathrm{pH} \sim 7.0$, c) synthesized EuAuNPs prepared with leaves extract Xenon irradiation for $1 \mathrm{~min}$ and $\mathrm{pH} \sim 7.0, \mathrm{~d}$ ) Relationship of excitation and emission wavelength of extract fluorophores in EuAg and EuAuNPs. 


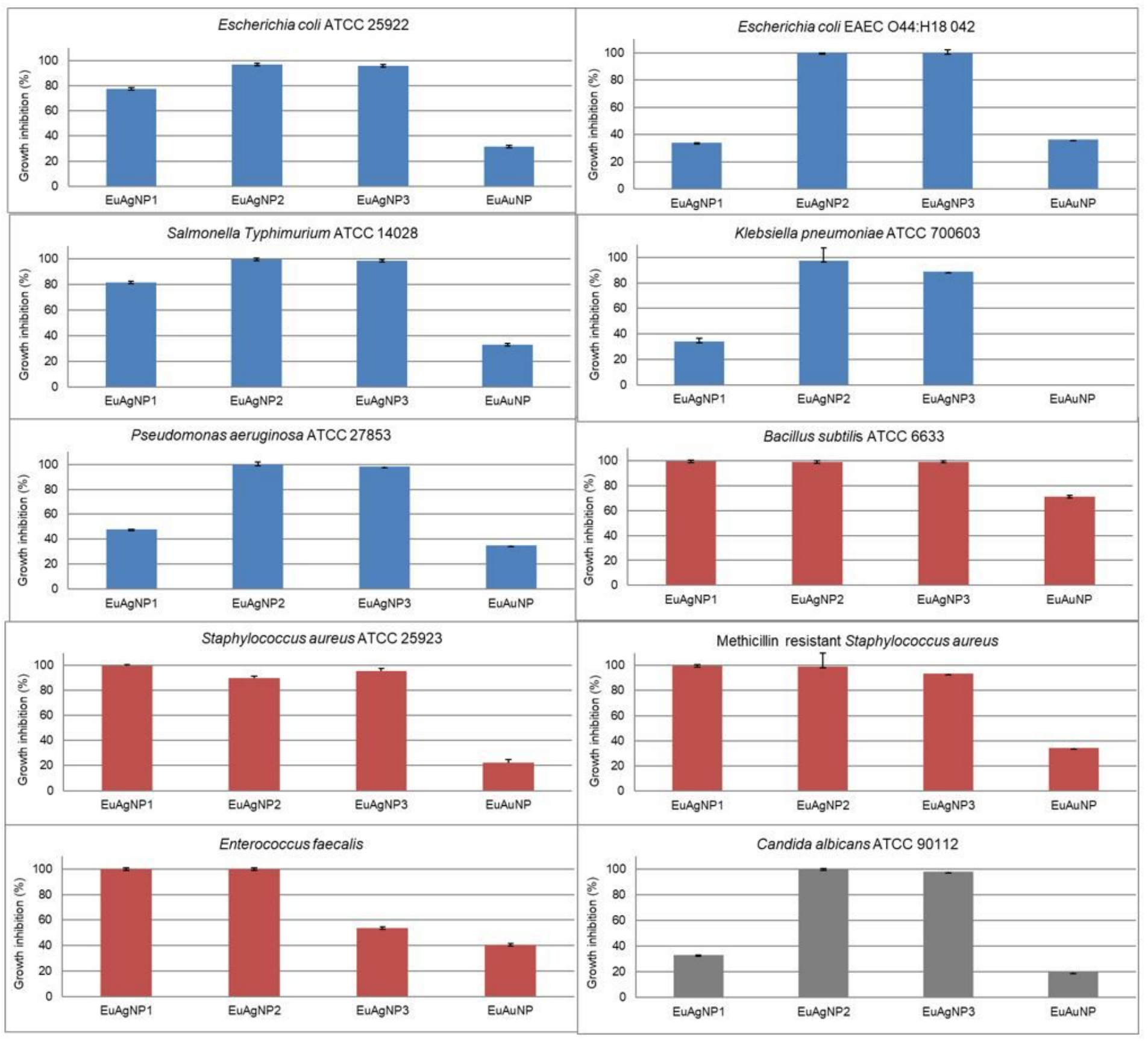

Figure 6

Antimicrobial activity of EuAgNP and EuAuNP against Escherichia coli ATCC 25922, Escherichia coli 044:H18 EAEC042, Salmonella Thiphymurium ATCC 14028, Klebsiella pneumoniae ATCC 700603, Pseudomonas aeruginosa ATCC 27853, Bacillus subtilis ATCC 6633, Staphylococcus aureus ATCC 25923, methicillin-resistant Staphylococcus aureus (MRSA), Enterococcus faecalis, and Candida albicans ATCC. 